\title{
The Public's Perceptions of a Cafe within the Social and Physical Context of a Residential Aged Care Facility
}

Alexa M. Andrew

Otago Polytechnic, alexa.andrew@op.ac.nz

Follow this and additional works at: https://nsuworks.nova.edu/ijahsp

Part of the Medicine and Health Sciences Commons

\section{Recommended Citation}

Andrew AM. The Public's Perceptions of a Cafe within the Social and Physical Context of a Residential Aged Care Facility. The Internet Journal of Allied Health Sciences and Practice. 2018 Jan 01;16(4), Article 11.

This Manuscript is brought to you for free and open access by the College of Health Care Sciences at NSUWorks. It has been accepted for inclusion in Internet Journal of Allied Health Sciences and Practice by an authorized editor of NSUWorks. For more information, please contact nsuworks@nova.edu. 


\title{
The Public's Perceptions of a Cafe within the Social and Physical Context of a Residential Aged Care Facility
}

\begin{abstract}
Background: The publics' perceptions of aged care residential facilities (ACRF's) are generally derogatory in nature; with terms such as the 'end of the road' or 'the last resort' being used to describe them. The institutional design and nature of the traditional 'nursing home' has contributed to such a perception. However, more contemporary models of residential aged care facilities are encompassing design features which aim to enhance the physical and social environment and therefore the lives of the older people residing within them.

Purpose: This research reports on the inclusion of a café in the foyer of an aged care residential which is open to the public. Members of the public who use the café were interviewed.

Methods: This research project utilised qualitative inquiry of a descriptive nature. Data was gathered through semi-structured interviews; seven participants were interviewed. Data analysis to establish themes utilised coding.

Findings: The perceptions of members of the public who use the café is presented according to three major themes; place and purpose, people and relationships and community exposure and perceptions. The café is perceived, by the participants of this research project, as a place to go in the local community which was appreciated for its familiarity, pleasant surroundings and the quality of its service. Interactions between staff and residents were observed as caring and participants reflected that the staff were personally invested in their work. Visiting this café has challenged the notion that ACRF's are closed off institutional places and the environment was described as open and inviting. The interaction between the community and the ACRF was discussed the benefits for the residents and for themselves were identified. Participants described a developing affiliation and connection between the facility and themselves and this prompted reflection about their own future residential needs.

Conclusion: This café has opened a door between the ACRF and the local community. Members of the public who visit the café are able to observe, interact and make connections within the residential care environment. Perceptions about the nature of aged care facilities have been challenged and reflection about future residential care needs has occurred.
\end{abstract}

\section{Author Bio(s)}

Alexa M. Andrew, MOccTher, is a senior occupational therapy lecturer at Te Ohu Ora College, Otago Polytechnic, New Zealand. 


\title{
1IVAHSP ${ }^{m-1}$ \\ The Internet Jouinal of Allied Health Sciences and Practice \\ Dedicated to allied health professional practice and education
}

Vol. 16 No. 4 ISSN 1540-580X

\section{The Public's Perceptions of a Café within the Social and Physical Context of a Residential Aged Care Facility}

Alexa M. Andrew, MOccTher

Otago Polytechnic

New Zealand

\begin{abstract}
Background: The public's perceptions of aged care residential facilities (ACRF's) are generally derogatory in nature with terms such as the "end of the road" or "the last resort" being used to describe them. The institutional design and nature of the traditional nursing home has contributed to such a perception. However, more contemporary models of residential aged care facilities are encompassing design features which aim to enhance the physical and social environment and therefore the lives of the older people residing within them. Purpose: This research reports on the inclusion of a café in the foyer of an aged care residential facility which is open to the public. Members of the public who use the café were interviewed. Methods: This research project utilised interpretive qualitative inquiry of a descriptive nature. Data was gathered through semi-structured interviews; seven participants were interviewed. Data analysis to establish themes utilised coding. Findings: The perceptions of members of the public who use the café are presented according to three major themes; place and purpose, people and relationships and community exposure and perceptions. The café was perceived by the participants of this research project as a place to go in the local community. It was appreciated for its familiarity, pleasant surroundings and the quality of its service. Interactions between staff and residents were observed as caring and participants reflected that staff were personally invested in their work. Visiting this café has challenged the notion that ACRF's are closed-off institutional places; the environment was described as open and inviting. The benefits of the interaction between the community and the ACRF were discussed and identified as relevant for both the residents and members of the public. Participants described a developing affiliation and connection between the facility and themselves and this prompted reflection about their own future residential needs. Conclusion: This café has opened a door between the ACRF and the local community. Members of the public who visit the café were able to observe, interact and make connections within the residential care environment. Perceptions about the nature of aged care facilities have been challenged and reflection about future residential care needs has occurred.
\end{abstract}

Key Words: Residential aged care, social environment, physical environment, community. 


\section{INTRODUCTION}

The fastest growing age group in society today, the 85 plus age group, can experience significant physical, cognitive, and sensory deficits resulting in the need for a supported living environment. ${ }^{1}$ The older people who live in residential care facilities are subject to stereotypical ageist attitudes, and their place of residence is seen as the "end of the road" or "the last resort." 2 Images of older people bedridden or sitting slumped in chairs lined up against the walls in an inactive state are commonplace. ${ }^{3}$ However, a paradigm shift in models of residential aged care has become evident in recent decades. The focus has shifted away from traditional institutional models of care to one where the aged care facility is perceived more as the older person's home. ${ }^{1}$ The physical and social environments of ACRF's are being reconceptualised and designed to facilitate opportunities for social engagement, participation in familiar activities of daily living, and the ability to maintain connections with the community. ${ }^{4,5}$ Various design features have been utilised to meet the aforementioned opportunities, and the focus of this research is a café in the foyer of an ACRF. Whether this fundamental shift in the delivery of residential aged care will have an impact on the public's attitudes remains to be seen.

\section{BACKGROUND}

The café referred to in this research was established in a large 124 bed ACRF during a process of major redesign and renovation. This large ACRF has five different units: two rest-home level care, two hospital level care, and one dementia care, each with its own dining area where residents eat their meals provided by the kitchen of the facility. Each unit also has a lounge area and other small visiting areas. The café is situated in the foyer at the front entrance of the ACRF and is open seven days a week from $8.30 \mathrm{am}$ to $5 \mathrm{pm}$ and services the residents of the facility, their family and friends, as well as being open to the public. The café consists of 3 distinct areas: indoor tables and chairs, comfortable couches in front of a fireplace, and an outdoor courtyard. The view from the café is the foyer of the ACRF, where the comings and goings of the facility are easily seen. The menu at the café offers barista coffee, tea, a variety of light meals, sandwiches and cakes, and is priced just below market rates. The café is funded and supervised by the management of the ACRF. The café offers a service which is in addition to the meal service the residents receive daily in the residential care environment. It was envisaged that the café being open to the public would create connections to and facilitate interactions with the local community. This article will discuss the findings of an interpretative qualitative research project which explored the public users' perceptions of the café within the context of this aged care facility.

\section{LITERATURE REVIEW \\ Perspectives of Older Adults}

The majority of literature available regarding public attitudes to residential aged care report on how older people themselves perceive residential aged care. Research from the United Kingdom (UK) suggests that older people perceive the need to move into residential care as "some sort of failure," 2 and that "they fear entering an ACRF more than dying itself." 6 Giving up one's home and moving into residential care is seen by the older person as compromising their identity, independence and control over their own lives. ${ }^{2}$ The aged care facility represents one of the most pervasive sources of anxiety in later life and fear is more pronounced among those who perceive that daily life in aged care is associated with a loss of control and dignity. ${ }^{7}$ Older people's perspectives about residential aged care are predominantly negative in nature and dominated by fear and anxiety. This research will explore the public's perspectives of one residential aged care facility with a café in situ.

Research conducted in Hong Kong exploring aged care related beliefs of Chinese older people found similar results. Eighty-five percent of the 118 older people interviewed would not want to live in a ACRF, and their beliefs regarding ACRF's were negative in nature. ${ }^{8}$ Participants expressed the notion that going into an ACRF would feel like they were being abandoned by their families, and this elicited feelings of insecurity and loneliness. Other major concerns related to a loss of privacy and freedom, and one participant stated that it would be "like living in jail." ${ }^{8}$ Further research identified that consideration of placement in an ACRF was a significant source of fear for Chinese older people especially for those whose health was deteriorating. ${ }^{9}$ Residential care was seen as the "ultimate dumping ground where one would idle until death."9 Other perspectives included a fear of arguments with staff and other residents, difficulty adapting to the routines and living environment, and being with "sick and strange old people."8 Attitudes of older people in Asia concur with those of the Western world - there is a pervasive sense of dread towards residential aged care.

The results of research exploring older peoples' attitudes towards residential care is not entirely negative, and a shift in perspective is beginning to become apparent. In research from Hong Kong that 
explored age-cohort differences on attitudes towards ACRF's, contrary to the studies hypothesis, older Chinese people reported more favorable attitudes to ACRF's than their younger cohorts. The older people acknowledged that the facilities provided comprehensive care to those with physical and cognitive needs. ${ }^{10}$ While the research by Tse found predominantly negative perspectives from older Chinese in relation to ACRF's, there was also evidence of some positive impressions. ${ }^{8}$ These included the presence of healthcare professionals to provide care, living with other older people who could support each other and share similar interests, and that an ACRF was a safe place to live. There is some evidence that older people are beginning to re-frame their perceptions of residential aged care through the recognition of the services it provides for older people with age-related decline.

\section{Perspectives of Other Age Groups}

Perspectives from a range of age groups have been explored in the United States of America (USA). A report titled The Public's Views on Long-Term Care collected information from a nationally representative random sample of 1,032 adults ages 18 and above. ${ }^{11}$ Interview questions focused on the quality of care, staffing, participants' experiences of ACRF's, and affordability of long-term care. Findings indicated that the public is wary of residential aged care - twice as many adults say being in an ACRF makes people worse off than they were before than those that say that it makes people better off. ${ }^{11}$ Marek and Rantz concur and state that "Dissatisfaction with the care of older people is widespread in the USA... 12" Negative attitudes towards residential aged care are not unique to the older age group; adults from a variety of age groups share fundamental concerns about the quality of the aged care industry. This research aims to explore the perspectives of the public from a variety of age groups.

\section{Design of Residential Aged Care Facilities}

The traditional aged care facility was referred to as a "nursing home," and the title itself is congruent with the notion that the older people who reside within them require nursing for their dependent and infirm conditions. The traditional design of nursing homes and some of the more recently built aged care facilities still reflect the medicalisation of ageing. Nursing home design based on a medical model are often clinical environments with nursing stations, sluice rooms, and kitchens where residents are not permitted to enter due to health and safety regulations. ${ }^{13}$ These environments are more reminiscent of a hospital setting which has been set up for the convenience of staff to carry out their nursing duties rather than a home designed for its residents to continue to participate in daily life. According to Davey, "It is increasingly accepted that traditional institutional care that keeps older people apart from society and 'medicalises' old age is no longer desirable and perpetuates a negative view of ageing."14 Incorporating a café into an aged care facility is one example of an innovation which attempts to break down the barriers between those older people who reside there and their local community.

Perspectives towards models of care and subsequent design of ACRF's are changing. The aged care residential environment is being seen through a new set of lenses, and the physical and social environment are being conceptualised as a resource to provide the older person with opportunities to continue living a meaningful life. ${ }^{15}$ The café, which is the focus of this research, is a design initiative where the transformation of the physical environment enhances the social environment. This facilitates opportunities for social engagement for the residents, staff, their friends and families and the public. ${ }^{5}$ Other single environmental initiatives that have been researched are more home-like dining, restaurant style dining areas, a bar, and renovation of outdoor spaces. ${ }^{16-19} \mathrm{~A}$ point of difference between the café and other environmental innovations is that the cafe is open to the public. Being open to the public increases the potential of increased interaction between the residents and members of the public who would have no other reason to visit the facility. Research projects such as this one are an important step in the development of an industry which is responsive to the needs of an ageing population in the $21^{\text {st }}$ century.

\section{Impact of Exposure to ACRF's}

Literature regarding the general public's responses to engagement with residential aged care facilities and its residents is sparse. The most common forms of contact between the public and residents of an ACRF involves volunteering to befriend older adults and intergenerational programmes. These programmes have a common strategy for reducing loneliness and increasing social opportunities for older adults in residential care. ${ }^{20}$ The success of these programmes is usually measured by the impact on the older adult and rarely in terms of the member of the public who has taken on the role of volunteer. However, one qualitative study which explored the impact of befriending on the volunteer, involved three post-graduate psychology students who befriended an older person living in an ACRF for a year.20 Findings indicated that the volunteers had developed close relationships with the older person and felt 
moved by their friendships. The volunteers described opportunities for discussion about personal and confronting issues and identified a developing awareness that they had made a difference in an older person's life. ${ }^{20}$ Intergenerational programmes which facilitate interactions between youth and older adults in ACRF's have also explored the impact on the young person. Blais et al conducted a literature review and concluded that benefits for youth include "the development of new communication and career-related skills, improved attitudes towards older adults and the development of meaningful relationships and friendships." 21 Therefore, research has demonstrated that the experience of close contact between the public and older people living in aged care can result in a positive and meaningful experience. This research project will expand the knowledge base of the impact of interaction between the public and the physical and social environment of an aged care facility.

Creating a society where older people are valued, respected and seen as contributing members of society is paramount in light of the ageing population. ${ }^{22}$ Challenging the ageist attitudes of society is a primary objective of The New Zealand Positive Ageing Strategy (2001). Objective eight states, "People of all ages have positive attitudes to ageing and older people."22 The researcher, an occupational therapist by profession, envisaged a number of benefits of having a café in an aged care residential facility open to the public. However, the researcher acknowledges her own bias as a result of professional enculturation and was interested in discovering the perceptions of the public users' of a café within an aged care facility. This article reports on stage three of this research project; the first stage explored the value of the café from the perspective of the residents and their family and friends, while the second stage explored the perceptions of staff members of the facility. 5,23

\section{METHODS}

The goal of qualitative inquiry is to make sense of the social world where multiple realities exist. ${ }^{24}$ This research utilised qualitative inquiry of an interpretive descriptive nature. Thorne et al describe this method as providing a foundation for the investigation of clinical phenomena of interest. ${ }^{25}$ Qualitative descriptive studies are particularly appropriate when relatively little is known about the research topic as they provide rich descriptions of phenomenon or events and stay close to the surface of the data. 26,27 Therefore, interpretive descriptive methodology is appropriate for this study which is exploring a developing area of inquiry.

Semi-structured interviews were planned as an appropriate method to explore the perspectives of the participants. ${ }^{28}$ In qualitative research, semi-structured interviews are often open-ended, revolving around a few key topics but otherwise guided by the participants and the information they share. . $9,30^{2}$ The use of open-ended interview questions allowed the researcher to explore and understand the experiences, attitudes, and viewpoints of the public users of the café. ${ }^{31}$ This type of questioning enables the researcher to be more informal during the interview process in order to make the participants feel at ease and talk freely about their perspectives.

\section{Participant Recruitment}

Potential participants consisted of all members of the public who use the café but do not have a relative or friend living at the facility. Family members or friends of residents who reside in the ACRF had previously been interviewed at an earlier stage of this research project. Recruitment occurred through a poster advertisement placed in the café. Potential participants were offered an inducement of two free drinks at the café to thank them for their time and effort. There were eight indications of interest and one participant did not meet the eligibility criteria due to having a relative living in the ACRF. Written informed consent was gained from all participants and anonymity was ensured through use of pseudonyms and the removal of any data that may render the participant identifiable to others. The study was approved by Otago Polytechnic Ethics Committee, reference number 656.

\section{Table One: Participant Demographic Details}

\begin{tabular}{|l|l|l|l|}
\hline Participant & Gender & Age Range & Ethnicity \\
\hline 1 & Female & $70-79$ & New Zealand European \\
\hline 2 & Male & $80-89$ & New Zealand European and Irish \\
\hline 3 & Female & $40-49$ & New Zealand European \\
\hline 4 & Female & $40-49$ & New Zealand European and Maori \\
\hline 5 & Female & $80-89$ & New Zealand European and German \\
\hline 6 & Female & $70-79$ & New Zealand European \\
\hline 7 & Female & $50-59$ & New Zealand European \\
\hline
\end{tabular}




\section{Data Gathering}

Six semi-structured interviews were conducted with seven participants; participants one and two were a married couple and elected to be interviewed together. The participants were provided with a choice regarding the venue of the interview; three participants elected to be interviewed in their own home, one elected their workplace, and three chose the café as a venue (one of whom had two of her young children present). When the interview occurred at the café, the researcher ensured that the radio was turned down and that the interview occurred in a quiet section of the café. The researcher took the opportunity to buy refreshment for the participant as well as herself, and the interview was conducted while having a cup of tea or coffee. The semi-structured interviews were conducted using a series of key questions which elicited the following information: why the participant used the café, their observations of daily life within the aged care facility, and the older people who reside within it and their perceptions about aged care facilities.

\section{Data Analysis}

Data analysis occurred according to the stages outlined by Marshall and Rossman: organising the data, immersion in the data, coding the data, writing analytic memos, and generation of themes. ${ }^{28}$ Stage one consisted of transcription of the interviews by a transcriber who signed a confidentiality form. In stage two the researcher immersed herself in the data by reading and re-reading the transcripts until in-depth familiarity of the data occurred. The third stage of coding included highlighting sections of interest in the transcript and writing analytic notes in the margin of the pages indicating potential links or similarity between excerpts of data. Codes were grouped into initial themes using a system of post-it-notes to visually organise the data. This iterative process continued with review, revision, and visual re-clustering of codes until themes were finalised. ${ }^{25}$ Peer examination occurred to check the fit between data and established themes and careful attention was paid during this process to protect participants' identities.

\section{RESULTS}

Participants are identified by the letter P and a number e.g. P3 or P6. Acorn Café and Acorn Home are pseudonyms for the name of the café and aged care facility. The findings are presented according to three themes: 1) place and purpose; 2) people and relationships; and 3) community exposure and perceptions.

\section{Themes}

Theme One: Place and Purpose

Participants referred to aspects of "place" when describing reasons why they chose to go to Acorn Café. Reasons for visiting included the convenience of its locality and proximity to other places in the local community. The setting and the physical environment were appreciated and described as attractive, sunny, bright, and warm, and the view of the garden from the café enhanced the environment. Participants reflected that the layout of the furniture in the cafe provided choice and was conducive to meeting with others. The atmosphere created by this environment was described as relaxing and quiet and compared to other cafes which were noisy and where the participants felt rushed. It is important to note that there are three other cafes within walking distance of Acorn Café which participants could choose to frequent.

P2: "It's just the setting and it's so nice, it's not noisy or anything, you go there to have a quiet coffee... and you can spend all day there..."

Familiarity with and attachment to the geographical area were also provided as reasons for visiting the café. Participants looked forward to inviting others and introducing them to the café which was seen as part of their local community. Returning to a place where a person has lived also prompted visits.

P6: "Probably because we have sentimental reasons for liking this area because my husband and I, our first home was just that way a little bit, in (name of suburb), so that's why we feel very comfortable about this."

The café was also perceived as a place which provides an appropriate venue to meet with residents in an ACRF. Participants commented on other facilities they visit where they struggle to find an appropriate place to visit with a resident.

P4: "...we had to meet her (the resident) in a communal area, there wasn't anywhere we could take her ..." 
The café provides an appropriate place for a social visit and is easily accessible for both parties.

One of the main purposes of a café is to provide food and drink, and the quality of this can be a primary factor in determining whether a person chooses to return. Participants commented on the quality of the presentation of the food and drink and that care is taken when serving it. The quality and uniqueness of the tea cups and home baking also contributed to the overall positive experience of visiting the café.

P7: "I really like the fact that the tea comes in really nice cups and actually the thing I think that they do really well is things like afternoon, you know, home baking, afternoon tea, that sort of thing."

Theme Two: People and Relationships

References to people and interactions between people emerged as a dominant theme. Several participants expressed their appreciation of the friendliness of the staff in the café, the positive nature in which the residents are treated and the quality of the service the staff provided.

P3: The staff are always really good to them [the residents], they know them by name and they know what they like and they know where their favourite seat is, that kind of thing. And I think that's really nice for the residents."

Participants reported having observed the communication style of a number of staff and the way in which they carried out their work. The range of staff included café workers, care worker staff, cleaning staff, kitchen staff, reception staff, and the manager. P2's reflections about the staff indicate that he perceived them as committed to their work and that they see the care of older people as more than just work, that they are personally invested.

P2: "The people that you meet there apart from the people that are servicing [the café] ... yeah they're pleasant and uh I don't know it seems more than a job to some of them down there you know."

Further reasons for using the café were related to the people participants take or meet with, in particular family and friends. The participants looked forward to introducing people from out of town to the café. Also recognised was that the café provided an opportunity for residents to meet with family or other visitors.

P4: "It's nice seeing some of the residents coming in and ordering their lunch and things, and family members meeting the residents here, you know, giving them a bit of a treat."

One participant specifically referred to the cultural elements of being able to offer visitors a cup of tea and that the café provides the opportunity to engage this particular aspect of a cultural norm.

P7: "One thing that I think about having the café is it means if I was in a rest home and my relatives came to visit me, I would want to give them a cup of tea because that's what our culture says...."

Theme Three: Community Exposure and Perceptions

The interaction between the people in the community and the residents of the aged care facility, which is facilitated by having a café open to the public, was seen as valuable by the participants.

P3: "And we've had a couple of chats with people who've been sat there [at the café] and they've seemed to be really enjoying themselves so I think it's probably a nice way for them to connect with community members and for us to connect with them".

Participants described community clubs, which they belong to, who now meet at the café to enable members who are now residents to continue to participate. This indicates that the public's perceptions of older people in aged care are people who still have the capacity and need for continued participation in groups with others who share a common interest.

Exposure to the residential care environment has prompted participants to think about the potential need for residential aged care for themselves or their loved ones. Participants expressed the notion 
that visiting Acorn café means that they have created a connection with this particular ACRF and that an affinity has been established.

P4: "...this specific place I think it does sort of perhaps plant a seed of an idea, 'oh a place like this would be good'... we've got an affinity with this place now ...."

Changing perceptions about the aged care facility were also clearly evident during the interviews. Participants discussed the change in their perceptions and reported that the presence of a café had transformed the facility into somewhere that is open and warm rather than closed or shut off.

P5:" ... it's more public, I didn't know anything about it and in a way it was a closed facility ... but if you are going to the café you're having a warmer feeling, an open feeling...."

\section{SUMMARY}

The café was perceived as a place to go in the local community which was appreciated for its familiarity, pleasant surroundings and quality food and drink. The social aspects of visiting the café were highlighted, interactions observed between staff and residents were seen as caring, and staff were perceived as personally invested in their work. The opportunities the cafe has created for interaction between the community and the ACRF were identified as beneficial for residents and members of the community. Visiting this café has challenged the notion that ACRF's are closed off institutional places; this café was described as creating an open and inviting environment. In addition, participants described developing an affiliation with the ACRF which at times prompted reflection about their own future residential needs.

\section{DISCUSSION}

Changing attitudes are challenging the traditional design of ACRF's which reflect a medical model of care and perpetuate attitudes which do not acknowledge older people as valued and integral members of the community. ${ }^{4,13,15}$ ACRF's are commonly situated within a suburb of a city or town, but pervasive negative attitudes and the clinical nature of the facilities design keeps it separate from local community life. The only people who normally enter an aged care facility are the residents, the staff members, visitors to the residents, or people delivering goods and services to the facility. Placing a part of the community (a café) within the walls of an ACRF is an innovative solution to opening its doors and increasing the integration between an ACRF and its surrounding community. Acorn café which is situated in the foyer of this ACRF is adjacent to the main reception area and acts as a central point of the facility. Situating a café at this vantage point provides a window into an otherwise hidden place from the local community.

Cafes are public places where people gather to be in the company of others, drink tea or coffee and are a part of people's regular routines and habits. ${ }^{26}$ Members of the public now have a reason to enter and spend time in this ACRF and integrate visits to Acorn café into the rhythm of their daily lives. Ensuring that ACRF's become a more integrated part of the local community is fundamental to increasing exposure between the public and older people who reside within them. Direct exposure to the environment of this ACRF allows the public to observe everyday life within the facility. McLafferty and Morrison suggest that frequent direct positive experiences with ACRF's would improve society's perspectives which are predominantly disparaging. ${ }^{11,12,33}$ Previous studies have demonstrated that engagement of the public through volunteer and befriending programmes with older people in ACRF's can result in a positive attitudinal changes towards older people. ${ }^{20,21,38}$ While changes in attitudes were not directly measured in this research, participants' perceptions of the residents reflected that they were perceived as active members of the community of the aged care facility, the wider local community, and their families. An illustration of this perception was the relocation of clubs or groups to the café which enables residents to continue to participate. The resident is still seen as an integral and contributing member of the group.

The major shift in attitude, evident in this research, was in relation to the concept of residential aged care; what was perceived as "closed and shut off" is now seen as "open and welcoming." This change in perception is facilitated by the transformation of the physical environment: the foyer which was previously simply functional has been reconceptualised and redeveloped..$^{15}$ The large sign outside the facility advertising the cafe provides a clear invitation to enter and beckons the public in. Once inside, the immediately visible café and its attractive and bright surroundings invites the public to step forward and enter the cafe. In addition to the physical cues of the environment, the social atmosphere created by staff and residents facilitates a feeling of inclusiveness. Participants in earlier stages of this research 
have identified the café as a "community hub," a place that people can feel a part of. What was seen as a clinical hospital-like environment to be entered with trepidation has been transformed into a place where all people are welcomed to participate in a pleasurable daily activity.

Research has indicated that many older people dread the need for residential aged care. One of the primary concerns are potential relationship difficulties with residents and staff in the aged care environment where the new resident is a stranger. ${ }^{8}$ Exposure to the nature of relationships within an ACRF may serve to reassure the public that ACRF's can be places where the quality of relationships is paramount. Participants' observations of the interactions between a variety of staff and residents in and around the café resulted in the impression that staff valued their relationships with residents. The relational aspects of care were also highlighted by participants in the earlier phases of this research project as an important aspect of the quality of this ACRF. Residents of the facility described the myriad of opportunities the café created for maintaining relationships and creating new ones with staff, other residents, and members of the local community. The opportunities created by the café to establish relationships was also of benefit to the family members of residents. Family described the sometimes stressful and emotional experience of having an older family member in aged care, and highlighted the emotional and practical support gained from connecting with other family members at the café. ${ }^{5}$ The social opportunities created by a café environment are ideal for the development and maintenance of meaningful relationships, and members of the public can participate in or simply experience the relational aspects of this environment.

Older people who are placed in a residential care facility usually do so under stressful circumstances; they may have experienced a significant health event, the death of a spouse, or can no longer manage independently in their own home. ${ }^{34}$ Entering an aged care facility, for those who have never had regular contact with one, could be a very daunting experience, and older people's primary response is one of fear. ${ }^{6,9}$ There is ample evidence about the harmful impact of transitioning into an ACRF; a high risk of developing late-life depression, anxiety and increased confusion. ${ }^{34,35}$ However, this outcome could potentially change if the older person has had regular contact with an ACRF as part of their daily lives prior to the need to relocate. Research has demonstrated that one of the most important determinants of adjustment to residential aged care is continuity in activities, habits, and relationships. ${ }^{34}$ Participants in this research have indicated their regular visits to the café have meant that they have developed a routine of visiting the ACRF to engage in a pleasurable leisure activity. The development of routines which are inclusive of an aged care facility may address older people's concerns about a loss of control and the need to adapt to new routines when entering an ACRF. ${ }^{2,7,8}$ The continuation of this regular activity in a familiar environment may provide some reassurance and a familiar base from which to adapt to their new place of residence. Ongoing relationships also play a part in experiencing continuity, and as discussed, participants have established relationships with people they visit the café with, café staff, and some of the residents. Changing perspectives of older people towards ACRF's which recognise the need for residential care ${ }^{1}$ have highlighted the potential of living with other people where there are opportunities for support and shared interests. ${ }^{1,8,10}$ The café is a place where relationships are established and the natural flow of conversation, which occurs in a social setting, can establish commonalities between people.

Further concerns of older people contemplating aged residential care are feelings of loneliness and insecurity, and research has demonstrated that successful integration into an ACRF is characterised by having established familiarity and a sense of belonging. ${ }^{8,36}$ As a result of spending time at the café, participants expressed feeling a sense of affinity to Acorn Home. Participants who looked forward to taking out of town visitors to the café clearly felt that the café was a part of their local community to be introduced to others. The café's contribution to developing a sense of community was also evident in the earlier stages of this research project. The residents, their families and the staff of Acorn Home described the café as having created a "community hub," a place that they can feel a part of. $5,23,37$ Experiencing a sense of belonging is vital for a new resident when transitioning into aged residential care, and the shared experience of community developed at the café could facilitate this process and occur prior to the relocation. The three older participants in this research (age $70-89$ ) reflected on the connection they had developed to this facility if in the future they needed residential care. Engaging in this thought process may contribute to an older person's preparation for entering aged residential care and challenge established negative perceptions.

Other innovative environmental solutions which encourage community integration have focused on bringing children into the aged care environment. ${ }^{39,40}$ The term Intergenerational Care refers to facilities 
which house older people as well as providing premises for a children's pre-school or day care and have been established in Japan, Canada, the United Kingdom, and United States. ${ }^{41}$ This is an exciting initiative where one building has a dual purpose and integration between older people and children is seamless. Many ACRF's have recognised the benefits of inviting children to spend time with residents and have established relationships with local kindergartens, play centres, or organised mother and baby sessions that residents are a part of. 39,40 The positive results of connecting older people with younger generations is well established; research has established that bringing older and younger people together reduces explicit and implicit attitudes to age. ${ }^{42}$ Positive contact between members of different social groups can limit the development of stereotypical attitudes and can foster social connectedness. ${ }^{6}$ The café also enables interaction between the residents and children: many children visit the café when visiting their grandparents, and those looking on can share in their presence.

Local communities, where aged care facilities are situated are also undergoing a process of change in line with changing attitudes towards health. Preventative approaches to health recognise a healthy community as one where "people come together to make their community better for themselves, their family, their friends, their neighbors, and others." ${ }^{43}$ In line with this definition of a healthy community, one of the most significant findings of the three stages of this research project is the sense of community, support, and connectedness that has been established as a result of frequenting the café. However, this initiative has been instigated by those who work with and recognise the needs of older people. The current approach to healthy community design does not yet appear to be inclusive of older people residing in residential care. Local community projects such as community gardens are commonly situated on local council grounds, alongside outpatient medical facilities, in schools, on church grounds, or on vacant lots. ${ }^{44-48}$ Including older people in projects such as a community garden, for example, would harness the established knowledge of a cohort of older people who have fed their families from growing food most of their lives. Men's sheds have also become a widespread community initiative, and research supports the mentoring process between older and younger men in this context. 49,50 There is, however, no current evidence that a men's shed has been established within the vicinity of an aged care facility. The potential for the development of community projects within the physical and social context of an aged care facility is limitless. Harnessing the knowledge and skills of older people residing in residential care within such community projects would create significant opportunities for ensuring that those older people are recognised as valuable, respected, and integral members of the community.

\section{LIMITATIONS}

This small scale qualitative interpretative descriptive study is of an exploratory nature, and the results do not claim to be generalizable to other settings. The participants were potentially biased from two perspectives. Firstly the participants consisted of a self-selecting group and those who have a positive viewpoint are more likely to volunteer, and secondly, a member of the public who chooses to visit a café in aged care facility is more likely to be open to the experience and therefore more amenable to developing a positive attitude.

\section{CONCLUSION}

Current models of residential aged care facilities which separate older people from the rest of society are being perceived as outdated and perpetuating negative views of ageing. The development of a society where older people are respected, valued, and integrated within their community until the end of their lives is imperative in a society which values its older inhabitants. Older people have the right to remain part of the community in which their identity and life roles are embedded, remain integrated with people of all ages and be able to live in places which enables this to occur. What is needed are innovative environmental solutions which break down barriers between the residential care environment and the local community and facilitate the continuation of an older person's quality of life rather than hindering it. More research is needed to explore and support the transition of ACRF's from institutions focused on the medicalisation of ageing to places where the life of the community is seamlessly bound with life within the aged care facility.

\section{References}

1. Miller EA, Booth M, Mor V. Meeting the demographic challenges ahead: toward culture change in an ageing New Zealand. Australia and New Zealand Health Policy. 2008;5(5). http://dx.doi.org/10.1186/1743-8462-5-5 
2. Oldman C, Quilgars D. The last resort? revisiting ideas about older people's living arrangements. Ageing Soc. 1999;19:363-384. https://search-proquest-

com.op.idm.oclc.org/docview/195632994?accountid=39660.

3. Harper-Ice G. Daily life in a nursing home: has it changed in 25 years? J Aging Stud 2002;16(4):34-59. https://search-proquest-om.op.idm.oclc.org/docview/228045516?accountid=39660.

4. Ragsdale V, McDougall GJ J. The changing face of long-term care: looking at the past decade. Issues In Mental Health Nursing [serial online]. September 2008;29(9):992-1001. Available from: CINAHL Complete, Ipswich, MA. Accessed April 27, 2018.

5. Andrew A, Wilson L. A café on the premises of an aged care facility: more than just froth? Scan $\mathrm{J}$ Occup Ther. 2014;21(3):219-226. doi:10.3109/11038128.2013.868034

6. Minney MJ, Ranzijn R. "We had a beautiful home . . but I think I'm happier here": a good or better life in residential aged care. Gerontologist. 2016;56(5):919. https://search-proquestcom.op.idm.oclc.org/docview/1824291185?accountid=39660.

7. Biedenharn P, Normoyle J. Elderly community residents' reactions to the nursing home: an analysis of nursing home-related beliefs. Gerontologist [serial online]. February 1991;31(1):107-115. Available from: CINAHL Complete, Ipswich, MA. Accessed April 27, 2018.

8. Tse MMY. Nursing home placement: Perspectives of community-dwelling older persons. J Clin Nurs. 2007;16(5):911. https://search-proquestcom.op.idm.oclc.org/docview/235006129?accountid=39660.

9. Lee D. Residential care placement: perceptions among elderly Chinese people in Hong Kong. J Adv Nurs. 1997;26(3):602-607. Available from: CINAHL Complete, Ipswich, MA. Accessed April 4, 2018

10.Tang CS, Wu AM, S., Yeung D, Yan E. Attitudes and intention toward old age home placement: a study of young adult, middle-aged, and older chinese. Ageing Int. 2009;34(4):237-251. doi: http://dx.doi.org/10.1007/s12126-009-9047-2.

11.Kaiser Family Foundation (2005). The public's views on long-term care. https://kaiserfamilyfoundation.files.wordpress.com/2013/01/7719.pdf Accessed May 3, 2018.

12. Marek K, Rantz M. Aging in place: a new model for long-term care. Nursing Administration Quarterly [serial online]. Spring2000;24(3):1-11. Available from: CINAHL Complete, Ipswich, MA. Accessed April 2, 2018.

13.Schwarz B. Designing public places for private lives: a study of the design process of long-term care settings [e-book]. University of Michigan; 1992. Available from: CINAHL Complete, Ipswich, MA. Accessed April 19, 2018.

14.Davey J. Ageing in place: the views of older homeowners on maintenance renovation and adaptation. Social Policy Journal of New Zealand. 2006:27: 128-141.

15.Peace S, Kellaher LA, Wilcocks DM. Re-evaluating residential care. Buckingham: Open University Press 1997.

16. Ducak K, Keller H, Sweatman G. Dining culture change in long-term care homes: transitioning to resident-centered and relational meals. Annals Of Long Term Care [serial online]. June 2015;23(6):28-36. Available from: CINAHL Complete, Ipswich, MA. Accessed April 4, 2018.

17.Kenkmann A, Hooper L. The restaurant within the home: experiences of a restaurant-style dining provision in residential homes for older people. Quality In Ageing \& Older Adults. 2012;13(2), 98-110. doi:10.1108/14717791211231184 
18. Leven NVT, Jonsson H. Doing and being in the atmosphere of the doing: environmental influences on occupational performance in a nursing home. Scan J Occup Ther [serial online]. November 2002;9(4):148-155. Available from: CINAHL Complete, Ipswich, MA. Accessed April 4, 2018

19. Bengtsson A, Carlsson G. Outdoor environments at three nursing homes: focus group interviews with staff. Journal Of Housing For The Elderly [serial online]. October 2005;19(3/4):49-69. Available from: CINAHL Complete, Ipswich, MA. Accessed April 2, 2018.

20.Stephens J, Simpson T, Holmes O, Collins R, Silver M, Bhar S. Volunteers befriending older adults in aged care residencies: three case studies. Australian Psychologist [serial online]. April 2016;51(2):164-170. Available from: CINAHL Complete, Ipswich, MA. Accessed April 27, 2018.

21.Blais S, McCleary L, Garcia L, Robitaille A. Examining the benefits of intergenerational volunteering in long-term care: a review of the literature. Journal Of Intergenerational Relationships [serial online]. July 2017;15(3):258-272. Available from: CINAHL Complete, Ipswich, MA. Accessed April 27, 2018.

22. Ministry of Social Development, (2001). Positive ageing in New Zealand: Diversity, participation and change. New Zealand: Author.

23. Andrew A, Foot-McKay A, Ritchie L. Staff perspectives of a café on the premises of an aged-care facility. Kai Tiaki Nursing Research [serial online]. January 2017;8(1):43. Available from: CINAHL Complete, Ipswich, MA. Accessed April 2, 2018.

24. Tolich M. Davidson C. Starting fieldwork: An introduction to qualitative research in New Zealand. Auckland: Oxford University Press 1999.

25. Thorne S. Data analysis in qualitative research. Evidence - Based Nursing. 2000;3(3):68. https://search.proquest.com/docview/1784038479?accountid=39660. doi: http://dx.doi.org/10.1136/ebn.3.3.68.

26. Grimes DA, Schulz KF. Descriptive studies: What they can and cannot do. The Lancet.2002;12(359):145-9. doi: 10.1016/S0140-6736(02)07373-7

27. Milne J, Oberle K. Enhancing rigor in qualitative description: a case study. Journal Of Wound, Ostomy \& Continence Nursing [serial online]. November 2005;32(6):413-420. Available from: CINAHL Complete, Ipswich, MA. Accessed August 21, 2018.

28. Marshall M, Rossman GB. Designing qualitative research. 5th ed. Los Angeles: Sage Publications 2011.

29.Leedy P, Ormrod J. Practical research: Planning and design. 7th ed. Upper Saddle River, NJ: Sage Publications 2001.

30.DiCicco-Bloom B, Crabtree BF. The qualitative research interview. Med Educ. 2006;40(4):314321. https://search.proquest.com/docview/202937729?accountid=39660.

31. Bailey CA. A guide to qualitative field research. 2nd ed. Thousand Oaks, CA: Pine Forge Press 2007.

32. Grafe C, Bollery F. Cafes and bars: the architecture of public display. New York: Routledge 2007.

33.McLafferty I, Morrison F. Attitudes towards hospitalized older adults. Journal Of Advanced Nursing [serial online]. August 15, 2004;47(4):446-453. Available from: CINAHL Complete, Ipswich, MA. Accessed April 19, 2018.

34. Koppitz A, Dreizler J, Imhof L, Altherr J, Bosshard G, Naef R. Relocation experiences with unplanned admission to a nursing home: a qualitative study. International Psychogeriatrics [serial online]. March 2017;29(3):517-527. Available from: CINAHL Complete, Ipswich, MA. Accessed April 28, 2018. 
35.Neufeld E, Freeman S, Joling K, Hirdes J. "When the Golden Years Are Blue": changes in depressive symptoms over time among older adults newly admitted to long-term care facilities. Clinical Gerontologist [serial online]. May 2014;37(3):298-315. Available from: CINAHL Complete, Ipswich, MA. Accessed April 23, 2018.

36. Cooney A. 'Finding home': a grounded theory on how older people 'find home' in long-term care settings. International Journal Of Older People Nursing [serial online]. September 2012;7(3):188-199. Available from: CINAHL Complete, Ipswich, MA. Accessed April 19, 2018.

37.Andrew A, Ritchie L. Culture change in aged-care facilities: a café's contribution to transforming the physical and social environment. Journal Of Housing For The Elderly [serial online]. January 2017;31(1):34-46. Available from: CINAHL Complete, Ipswich, MA. Accessed April 28, 2018.

38.Lyons, I. Public perceptions of older people and ageing: a literature review. 2009. National center for the protection of older people.

http://www.ncpop.ie/Year\%201\%20Reports/Microsoft\%20Word\%20-

\%20NCPOP\%20Lit\%20Rev\%201\%20IL\%2001 12 09Cover\%20inc22 01 10.pdf

39. Brownie S. A culture change in aged care: The Eden Alternative ${ }^{\mathrm{TM}}$. Australian Journal Of Advanced Nursing [serial online]. September 2011;29(1):63-68. Available from: CINAHL Complete, Ipswich, MA. Accessed April 4, 2018.

40.Di Bona L, Kennedy S, Mountain G. Adopt a care home: an intergenerational initiative bringing children into care homes. Dementia. August 28, 2017.

41.The Atlantic. The preschool inside a nursing home. https://www.theatlantic.com/education/archive/2016/01/the-preschool-inside-a-nursing-home/424827/ Accessed August, 2018

42.Abrams D, Swift HJ, Lamont RA, Drury L. The barriers and enablers of positive attitudes to ageing and older people, at the societal and individual level. University of Kent. January 2015.

https://assets.publishing.service.gov.uk/government/uploads/system/uploads/attachment data/file/45 4735/gs-15-15-future-ageing-attitudes-barriers-enablers-er06.pdf

43. Health resources in action. Advancing public health and medical research. https://hria.org/wp-content/uploads/2016/10/defininghealthycommunities.original.pdf Accessed August 20, 2018.

44.Twiss J, Dickinson J, Duma S, Kleinman T, Paulsen H, Rilveria L. Field action report. Community gardens: lessons learned from California healthy cities and communities. American Journal Of Public Health [serial online]. September 2003;93(9):1435-1438. Available from: CINAHL Complete, Ipswich, MA. Accessed August 24, 2018.

45. Milliron B, Vitolins M, Gamble E, Jones R, Chenault M, Tooze J. Process Evaluation of a Community Garden at an Urban Outpatient Clinic. Journal Of Community Health [serial online]. August 2017;42(4):639-648. Available from: CINAHL Complete, Ipswich, MA. Accessed August 23, 2018.

46. Guitart D, Pickering C, Byrne J. Color me healthy: food diversity in school community gardens in two rapidly urbanising Australian cities. Health \& Place [serial online]. March 2014;26:110-117. Available from: CINAHL Complete, Ipswich, MA. Accessed August 23, 2018.

47. Hartwig K, Mason M. Community Gardens for Refugee and Immigrant Communities as a Means of Health Promotion. Journal Of Community Health [serial online]. December 2016;41(6):1153-1159. Available from: CINAHL Complete, Ipswich, MA. Accessed August 23, 2018.

48. McCabe A. Community gardens to fight urban youth crime and stabilize neighborhoods. International Journal Of Child Health \& Human Development [serial online]. July 2014;7(3):223-236. Available from: CINAHL Complete, Ipswich, MA. Accessed August 23, 2018.

49. Cordier R, Wilson N, Falkmer T, et al. Formal intergenerational mentoring at Australian Men's Sheds: a targeted survey about mentees, mentors, programmes and quality. Health \& Social Care In 
The Community [serial online]. November 2016;24(6):e131-e143. Available from: CINAHL Complete, Ipswich, MA. Accessed August 23, 2018.

50.Rahja M, Scanlan J, Wilson N, Cordier R. Fostering transition to adulthood for young Australian males: an exploratory study of Men's Sheds' intergenerational mentoring programmes. Australian Occupational Therapy Journal [serial online]. June 2016;63(3):175-185. Available from: CINAHL Complete, Ipswich, MA. Accessed August 23, 2018. 